\title{
Spatial Ability Differences in Athletes and Non-Athletes
}

\author{
Jessica Cynthia, ${ }^{1}$ Leonardo Lubis, ${ }^{2}$ Vitriana $^{3}$ \\ ${ }^{1}$ Faculty of Medicine Universitas Padjadjaran, ${ }^{2}$ Department of Anatomy and Cell Biology Faculty \\ of Medicine, Universitas Padjadjaran, ${ }^{3}$ Department of Physical Medicine and Rehabilition Faculty \\ of Medicine Universitas Padjadjaran/Dr. Hasan Sadikin General Hospital, Bandung
}

\begin{abstract}
Background: Cognitive processes, specifically spatial abilities, are responsible for integration of daily activities. Many factors contribute to the plasticity of the brain which, furthermore, alter the spatial ability. Physical activity, which can be further grouped into sport and exercise, is a modifiable factor that enhances the cognitive processes through a divergent mechanism. This study aimed to gain further understanding on whether sport differs from exercise in altering spatial ability in athletes and non-athletes.

Methods: This observational study compared the spatial ability score of athletes of Indonesia National Sport Comitte (Komite Olahraga Nasional Indonesia, KONI) in West Java $(\mathrm{n}=21)$ and non-athletes $(\mathrm{n}=21)$. Sampling were performed using stratified random technique and data were collected between August and October 2015 which included spatial scores and demographic of subjects.

Results: The difference in spatial scores between athletes and non-athletes were not significant $(p=0.432)$. Conclusions: This study suggests an insignificant difference in spatial ability in athletes performing sport and non-athletes performing exercise. Hence, the cognitive component skills in sport experience do not alter the spatial ability. [AM].2016;3(4):533-7]
\end{abstract}

Keywords: Athlete, cognitive, exercise, spatial, sport

\section{Introduction}

Spatial ability is a subcategory of cognitive processes which affects various aspects of human's life. It is not of a definite value since it is formed by persistent changes occured in brain neurones and involves more than one part of the brains. Many factors take part in the morphological changes of the brain, among them are sport and exercise which are parts of physical activities. ${ }^{1,2}$ Although they may seem similar, they affect the spatial ability through different mechanisms.

Exercise which is performed by nonathletes has long been supported by a lot of scientific evidence to increase the physical fitness, hence spatial ability. ${ }^{3}$ The mechanisms proposed include transient increase of brain-derived neurotrophic factor (BDNF) that promotes the plasticity of brain, increased hippocampal volume, and increased cardiovascular health, which in turn increases the VO2 max in the brain. ${ }^{2,4,5}$ Athletes performing sports, in addition to having physical fitness, are hypothesized to be superior in cognitive skills than those who are sedentary. Although athletes are known to have "expert performance" or "narrow transfer" which leads tocognition expertise within a particular field, i.e. sports, limited knowledge is available on whether the "broad transfer" or "cognitive component skills" also occur and contribute to increased spatial ability of athletes outside the sport field. .,7,8 $^{-1}$

This study aimed to further the knowledge on how sport differs from exercise in altering the spatial ability in general setting between athletes and non-athletes through spatial ability score measurement.

\section{Methods}

This was an observational study involving athletes and non-athletes recruited during the period of August to October 2015. Ethical approval was given by the Health Research Ethics Committee, Faculty of Medicine, Universitas Padjadjaran and informed consent was signed prior to participation in this study.

Correspondence: Jessica Cynthia, Faculty of Medicine, Universitas Padjadjaran, Jalan Raya Bandung-Sumedang Km.21, Jatinangor, Sumedang, Indonesia, Phone: +62 87821911198 Email: jessica.cynthia94@gmail.com 
Athletes were recruited from of the Indonesian National Sport Comitte (Komite Olahraga Nasional Indonesia, KONI) West Java which who were going to participate in the national tournament, the National Sport Weeks (Pekan Olahraga Nasional, PON) 2016. A total of 32 athletes from 11 types of sports were sampled using the stratified random sampling method. Non-athletes were students of the Faculty of Medicine, Universitas Padjadjaran. A total 21 students who fullfilled the criteria of routine exercise based on the American College of Sport Medicine (ACSM) standard for at least 6 weeks were recruited. The inclusion criteria of the subjects were 18-25 years old, did not consume illicit drugs based on self-report, and no history of neurological disorders. Athlete subjects were excluded if they did not follow sport programs routinely, while non-athlete subjects were disqualifed if there was a history of being an athlete in any institution.

Physical activities weremeasured for nonathletes to eliminate sedentary subjects using Global Physical Activity Quistionaire (GPAQ) issued by World Health Organization (WHO) that already being translated and tested to 20 participants with similar characteristics to the study subjects and had been shown to be valid and reliable. Through interview with subjects, the metabolic equivalent (MET) score showing level of physical activities was gained.

The ACSM classified exercise into four domains; aerobic exercise, resistance exercise, flexibility exercise, and neurologic exercise. ${ }^{9}$ Each exercise is aimed at different aspects of physical fitness and is unique in terms of the recommended frequency to achieve its goal; yet, all exercises has been demonstrated to increase the cognition, specifically the spatial cognitive ability.

For cardiorespiratory exercise, the evidence-based recommendations for frequency are $\geq 5$ days per week of moderate exercise or $\geq 3$ days per week of vigorous exercise, moderate and/or vigorous intensity and 30-60 minutes per day $(<150$ minutes per week) of purposeful moderate exercise or 2060 minutes (75 minutes per week) of vigorous exercise. The type of exercises include regular, purposeful exercises that involve the major muscle group and are continuous and rhytmic in nature.

For resistance exercise, the evidence-based recommendations are each major muscle group should be trained 2-3 days per week, with an intensity of $60-70 \%$ of 1 repetition maximum (RM). The resistance exercise involves major muscles with no specific duration of time for one exercise period.

For the flexibility exercise, the evidencebased recommendations are $\geq 2-3$ days per week, stretch to a point of feeling thightness or slight discomfort, then hold a static stretch for 10-30 seconds and exercise for each major muscle-tendon.

Sport is defined as different from other physical training; it is a structured, gradual, and continous program that construct and encourage athletes through competitions to achieve accomplishment. ${ }^{10}$ Therefore, athletes have a distinct characteristic, that is a high tendency to upgrade themselves to a very high level of exertion for a long period of time and beyond their native physical abilities. This is achieved through a systematic training program given by an institution. The institution, KONI in this study, provided a training program consisting of two components: health related physical fitness and skill related physical fitness specific to the sport type ${ }^{11}$ There were 11 sport types in this study; fencing, athletic, wrestling, judo, kempo, weight lifting, archery, rock climbing, silat, gymnastic, and taekwondo.

The spatial ability was measured for both athletes and non-athhletes, using Helen Bristoll spatial ability test. This written test is consisted of several types of question regarding spatial abilities with a total of 45 questions to be answered in up to 20 minutes. The types are shape matching, group rotation, combining shapes, cube views in 3D, solids in 2D, solids in 3D, and maps. Each correct answet will get one point, while wrong or emptied answer will get zero point. The questions were translated and tested to 30 participants with similar characteristics of the subjects of this study and has been shown to be valid and reliable $(\alpha=0.703)$.

For athlete participants, after confirming the participation in KONI, physical features were measured, i.e. weight and height. Spatial testing was performed in KONI office with sufficient lighting and closed doors and windows to prevent distractions. Before the test, instructions were given and the participants were ensured to have understood the tasks. For non-athletes participants, GPAQ was given first to measure the physical activities and only eligible participants can pass the spatial test. Spatial testing and physical feature measurement were conducted in one of the classroom of the faculty of medicine sufficient lighting. Instructions were also given before the test begin. 


\section{Athletes}

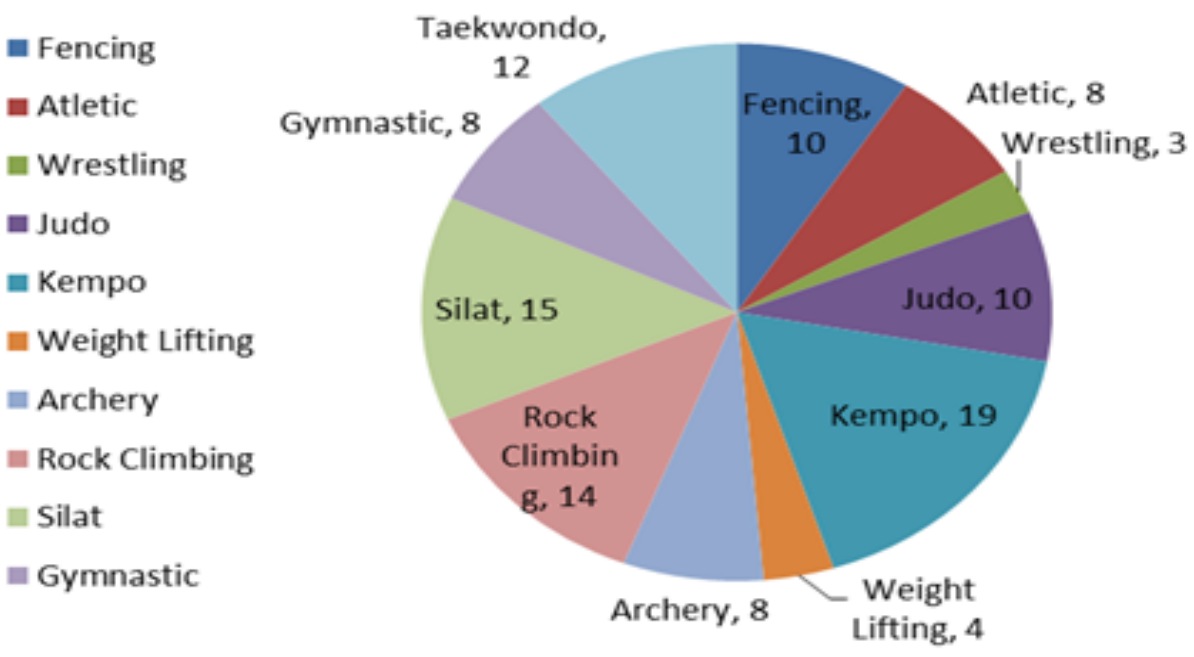

Figure 1 Sport Compositions of Athlete Group

\section{Results}

Average age of athletes and non-athletes was similar, that was in their 20s. This also applied to characteristics of weight and height. BMI was higher for athletes, probably due to the presence of weight training athletes with large figures. The physical activities of non-athletes showed no sedentary participants and all were in moderate physical activity range $(600 \leq \mathrm{x}$ $<3000$ ). The physical exercises completed by non-athletes were more than 6 weeks which was the inclusion criteria, with a minimum value of 6 weeks and a maximum value of 152 weeks.
The spatial scores were analyzed using Mann Whitney test. In table 2, non athlete group was shown to have better spatial scores with a margin of 1 compared to the athlete group. Nevertheless, the difference was not significant $(p>0.05)$, thus failed to prove that there was a difference in spatial ability between athletes and non-athletes.

\section{Discussions}

Currently, an agreement is not yet achieved on the cognitive transfer skills and impact. This study aimed to acknowledge whether skills

Table 1 Characteristics of Athlete and Non-Athlete Groups

\begin{tabular}{lcccc}
\hline \multirow{2}{*}{ Characteristics } & \multicolumn{2}{c}{ Athlete $(\mathbf{n = 2 1 )}$} & \multicolumn{2}{c}{ Non-Athlete (n=21) } \\
\cline { 2 - 5 } & Mean & $\begin{array}{c}\text { Standard } \\
\text { Deviation }\end{array}$ & Mean & $\begin{array}{c}\text { Standard } \\
\text { Deviation }\end{array}$ \\
\hline Age, years & 22 & 1.97 & 21.10 & 0.44 \\
Height, m & 164.19 & 7.64 & 167.76 & 9.67 \\
Weight, kg & 68.14 & 20.76 & 65.24 & 12.69 \\
BMI, kg/m2 & 24.71 & 7.56 & 22.43 & 3.04 \\
Physical Activity, MET & - & - & 2703.81 & 1481.83 \\
-week & - & - & 37.57 & 49.37 \\
Physical Exercise, weeks & - & 3.10 & & \\
Sport experience, years & 6.72 & & &
\end{tabular}


Table 2 Mann Whitney Analysis Result

\begin{tabular}{|c|c|c|c|c|}
\hline \multirow[b]{2}{*}{ Spatial Score } & \multicolumn{2}{|c|}{ Spatial Score } & \multirow[b]{2}{*}{ ZM-W } & \multirow[b]{2}{*}{ P Value } \\
\hline & $\begin{array}{l}\text { Athlete } \\
(n=21)\end{array}$ & $\begin{array}{c}\text { Non Athlete } \\
(n=21)\end{array}$ & & \\
\hline Median \pm SD & $33 \pm 5.03$ & $34 \pm 3.45$ & & \\
\hline Range & 20 & 11 & & \\
\hline
\end{tabular}

obtained from sport can be transferred to increase spatial ability. The specific population that does sport is athlete population, but they are not only trained in specific skills regarding their sport field but also do physical exercise to increase physical fitness. Physical exercise, mainly cardiorespiratory exercise and resistance exercise, has been observed to increase spatial abilities. To eliminate the effect of exercise on spatial ability and, in order to highlight the effect of sport only, exercised non-athlete control was chosen.

The hypothesis of the current study is not supported by the results obtained. The spatial ability of the athletes and non athletes is not significantly differ from one another. This may suggests that exercise may or may not increase the spatial ability of both groups but specific sport skills did not additionally affect the spatial ability of athletes.

The result of this study is in concordance with a previous study regarding cognitive transfer skill. In a study by Jansen and Lehman ${ }^{12}$, a comparison between soccer players $(n=40)$, gymnasts $(n=40)$, and non athletes $(n=40)$ was performed. The non-athlete controls also do sport with less training experience period. There is no significant difference of mental rotation performance between athletes and non-athletes.

A previous study by Chaddok et $a{ }^{13}$ has mentioned the presence of cognitive transfer skill as the results of different characteristics between athletes and non-athletes in the study. The groups compared were athletes $(n=18)$ and non-athletes $(\mathrm{n}=18)$, in which the nonathlete group was close to none in sport and weight training experience, while the athlete group was superior in both exercise and sport period. The result showed that the athlete group was superior than the non-athlete group in every day task such as crossing road, which is not a sport skill. This suggested the presence of cognitive transfer; yet, this may be misleading due to the assumption that the excellent cognitive of the athletes was due to sport skills only, when actually athletes were also superior in exercise. Exercise only has been proposed by many studies to have significant effects in increasing cognitive. ${ }^{2}$

A mechanism that is proposed as a mechanism that can increase the spatial cognition is increasing the grey matters of the brain, specifically hippocampus, which is involved in the spatial processing. ${ }^{14}$ The increasing size may be related to the increase of BDNF. thus increasing the synaptic connection and the physical fitness that increases the oxygen flows to the brain. ${ }^{4,5}$ Nevertheless, studies showed that both athletes and exercised non-athletes have superior hippocampal volume than that of sedentary control. ${ }^{15}$ This may explain the result findings in this study, in which no significance difference inspatial ability is found in subjects who do sports and exercises although future studies might be needed to clarify the difference in the alteration of hippocampal volume between subjects who do sports only, and subjects who only do exercises without sport using the preand post- intervention design.

Other alteration occured is the alteration of the higher integrative function which is in line with the cognitive component skills. One most widely examined component is P3 (also called P300 or P3b), which is an important component of information integration in working memory. Spatial working memory is the highlight in this study, among other type of working memories. In both exercise and sport subjects, when compared to sedentary subjects, studies showed the presence of superior P3 process, faster P3 latency associated with cognitive processing speed, and larger P3 amplitude associated with attention in engaging a stimulus or task. ${ }^{1}$ This may indicate that exercise and sport exert the same pathway in increasing spatial with no cognitive transfer skills occured. Yet, similar to the case of increased grey matter volume clarification through direct comparison of P3 values between sport and exercise groups is needed through pre- and post-intervention study.

This study has limitations in scope and depth. The number of participants is more than the minimum number of sample size required by sample size calculation for independent 
numeric analysis. Yet, bigger sample size could yield stronger statistical power. Moreover, non-athlete group consists of medical college students which might not be representative of general population, since the athlete counterparts come from different majors in college. For future studies, bigger number of participants with diverse background is recommended. Lastly, since this study is a cross sectional expertiment, no causality can be determined and the justification for the results can only be speculated from literatures. A study using pretest-posttest experimental design for athletes and non athletes, which also compares types of different sport, is recomended for a future study using homogenous frequency and intensity of exercise.

In summary, this study proves that cognitive transfer skills in sports towards the spatial ability is either non-existance or insignificant. This study proposes that sport and exercise increase the spatial ability through the same mechanisms, though future study may clarify the different magnitude of effect from both groups in order to obtain the optimal dose in which sport or exercise could have beneficial effect on cognition, specifically for the spatial ability.

\section{References}

1. Nakata H, Yoshie M, Miura A, Kudo K. Characteristics of the athletes' brain: evidence from neurophysiology and neuroimaging. Brain Res Rev.2010;62(2):197-211.

2. Erickson KI, Voss MW, Prakash RS, Basak C, Szabo A, Chaddock L, et al. Exercise training increases size of hippocampus and improves memory. Proc Natl Acad Sci U S A. 2011;108(7):3017-22.

3. Voss MW, Heo S, Prakash RS, Erickson KI, Alves H, Chaddock L, et al. The influence of aerobic fitness on cerebral white matter integrity and cognitive function in older adults: results of a one year exercise intervention. Human Brain Mapping. 2013; 34(11):2972-85.

4. Piepmeier AT, Etnier JL. Brain-derived neurotrophic factor (BDNF) as a potential mechanism of the effects of acute exercise on cognitive performance. J Sport Heal Sci. 2014;4(1):14-23.

5. Young J, Angevaren M, Rusted J, Tabet N.
Aerobic exercise to improve cognitive function in older people without known cognitive impairment. Cochrane Database of Syst Rev. 2015;4(1):CD005381.

6. Jin H, Xu G, Zhang JX, Gao H, Ye Z, Wang $P$, et al. Neuroscience Letters Eventrelated potential effects of superior action anticipation in professional badminton players. Neurosci Lett. 2011;492(3):13944.

7. Voss MW, Kramer AF, Basak C, Prakash RS, Roberts B. Are expert athletes " expert" in the cognitive laboratory? A meta-analytic review of cognition and sport expertise. Appl Cognit Psychol.2009;24:812-826

8. Alves H, Voss MW, Boot WR, Deslandes A, Cossich V, Salles JI, et al. Perceptualcognitive expertise in elite volleyball players. Front Psychol. 2013;4(1):36.

9. Garber CE, Blissmer B, Deschenes MR, Franklin B a., Lamonte MJ, Lee IM, et al. Quantity and quality of exercise for developing and maintaining cardiorespiratory, musculoskeletal, and neuromotor fitness in apparently healthy adults: guidance for prescribing exercise. Med Sci Sports Exerc. 2011;43(7):133459.

10. Presiden Republik Indonesia, Dewan Perwakilan Rakyat. Undang-Undang Republik Indonesia no 3 Tahun 2005 Tentang Sistem Keolahragaan Nasional. Jakarta: Negara Republik Indonesia; 2005.

11. Bushman BA,editor. ACSM's complete guide to fitness \&health. Illinois: Human Kinetics; 2011.

12. Jansen P, Lehmann J. Mental rotation performance in soccer players and gymnasts in an object-based mental rotation task. Adv Cogn Psychol. 2013;9(2):92-8.

13. Chaddock L, Neider MB, Voss MW, Gaspar JG, Kramer AF. Do athletes excel at everyday tasks?. Med Sci Sport Exerc. 2011;43(10):1920-6.

14. Hartley T, Lever C, Burgess N, O'Keefe J. Space in the brain: how the hippocampal formation supports spatial cognition. Philos Trans R Soc Lond B Biol Sci. 2013;369(1635):20120510.

15. Wei G, Zhang Y, Jiang T, Luo J. Increased cortical thickness in sports experts: A comparison of diving players with the controls. PLoS One. 2011;6(2):e17112. 